\title{
Prevalence of metabolic syndrome and associated risk factors in Brazilian schoolchildren
}

\author{
Mario Seki ${ }^{1}$, Tiemi Matsuo ${ }^{2}$ and Alexandre Jose Faria Carrilho ${ }^{1, *}$ \\ 'Department of Internal Medicine, Health Science Center, Londrina State University, Londrina 86038-440, \\ Paraná, Brazil: ${ }^{2}$ Department of Statistics, Londrina State University, Londrina, Parana, Brazil
}

Submitted 26 0ctober 2007: Accepted 3 April 2008: First published online 24 July 2008

\begin{abstract}
Objective: To determine the prevalence of metabolic syndrome (MetS) in schoolchildren from 6 to 16 years old, while considering their socio-economic status and other potential risk factors.

Design: A cross-sectional study was conducted between April and November of 2005 in a semi-rural city with a total population of 13000 inhabitants.

Setting: The study was conducted in Maracai city, located in the Brazilian state of Sao Paulo.

Subjects: Schoolchildren ( $n$ 2170) of both genders, corresponding to approximately $82 \%$ of all Maracai schoolchildren, were evaluated for components of MetS, as defined by the National Cholesterol Education Program; reference values for children and adolescents were adjusted for age and sex.

Results: Overall, MetS prevalence was 3.6\% (95\% CI 2.9, 4.5) and did not differ statistically between genders, skin colour, between children and adolescents. However, when we analysed groups of subjects by weight, MetS prevalence progressively increased from $0.3 \%(95 \% \mathrm{CI} 0 \cdot 1,0 \cdot 8)$ in normal-weight subjects to $10 \cdot 7 \%(95 \%$ CI $7 \cdot 4,14 \cdot 8)$ and $34 \cdot 5 \%(95 \%$ CI $25 \cdot 9,43 \cdot 9)$ in overweight and obese subjects, respectively (both $P<0.001$ compared to normal-weight controls). When socio-economic classes were considered, $4 \cdot 7 \%$ high-income students $(95 \%$ CI $3 \cdot 5,6 \cdot 2)$ had MetS, which was significantly greater than low-income students $(2 \cdot 7 \% ; 95 \%$ CI $1 \cdot 9,3 \cdot 9 ; P=0 \cdot 023)$.

Conclusions: MetS prevalence was high in overweight and obese schoolchildren and these risk factors were present during childhood and adolescence. Changes in lifestyle and alimentary safety should be encouraged to avoid future cardiovascular morbidity and type 2 diabetes mellitus.
\end{abstract}

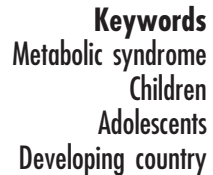

Metabolic syndrome (MetS) is a general metabolic disorder associated with central obesity, insulin resistance and greater risk for CVD in adults ${ }^{(1,2)}$. However, the coexistence of these multiple cardiovascular risk variables also occurs in children ${ }^{(3)}$, with obesity often preceding the hyperinsulinaemic state ${ }^{(4,5)}$. It is well documented that MetS can be detected in childhood and its prevalence has been increasing around the world, in parallel with the elevated incidence of overweight and obese adults ${ }^{(6)}$ and children $^{(7)}$. This phenomenon is well known in developed countries and seems to be happening in developing nations as well, especially among populations that have adopted the Western lifestyle. However, data concerning MetS prevalence in low- and middle-income countries are still scarce, mainly in children and adolescents ${ }^{(8)}$. Assuming that childhood obesity and related co-morbidity will increase the impact of cardiovascular risk in adult diseases, it is essential to further our knowledge of MetS prevalence in children and adolescents of developing countries.
Despite significant efforts to unify the cut-off points for MetS variables and definitions of MetS, these parameters remain debatable, especially for children and adolescents, but in adults as well. In adults, these MetS variables include measures of insulin resistance, as stated by the $\mathrm{WHO}^{(9)}$ and the European Group for the Study of Insulin Resistance $^{(10)}$. The National Cholesterol Education Program Adult Treatment Panel III (NCEP-ATP III) ${ }^{(1)}$ defines MetS as the presence of three or more of the following criteria: low HDL cholesterol (HDL-C), hypertriacylglycerolaemia, hypertension, glucose intolerance and visceral obesity. The most recent MetS definition used by the International Diabetes Federation ${ }^{(11)}$ requires central obesity plus two of the above criteria.

The definitions accepted for the paediatric population are derived from adult cut-off points and adjusted for age and sex; however, neither insulin concentration nor central obesity is clearly defined in children. Therefore, the aim of the present study was to estimate the 
prevalence of MetS in schoolchildren aged 6-16 years living in Maracai city of Sao Paulo state in south-eastern Brazil, according to the NCEP-ATP III definition adjusted for children and adolescents and considering socioeconomic class and skin colour.

\section{Methods}

\section{Study design and subjects}

This investigation was a cross-sectional study conducted between April and November of 2005 in Maracai, a semirural city located in Sao Paulo State, with a total population of 13000 inhabitants (Geographic and Statistic Brazilian Institute - IBGE, 2000 Census). All schoolchildren aged 6-16 years who were matriculated in eight schools (seven public and one private), comprising 100\% of the city's teaching institutions, were invited to participate in the study ( $n$ 2647). Of this population, 434 students (248 males and 186 females) did not join the study, leaving 2213 students who were initially included. Of the 2213 students, twenty-five were excluded for reaching the exclusion criteria of severe illness, suffering from diseases (renal, hepatic or metabolic) that interfere with lipid metabolism, and pregnancy. An additional eighteen were excluded for irregularities in filling the protocol or in collecting data or blood. Thus, the final study sample consisted of 2170 students (1103 males, 1067 females), corresponding to $83.3 \%$ and $81.9 \%$ per gender, respectively, of all schoolchildren from 6 to 16 years old in the city. Informed consent was obtained from the participants or their parents and the study protocol was approved by the North Parana University Hospital Ethical Committee.

All measurements were performed by trained nurses. Height and weight were determined in duplicate while participants were in underclothes without shoes. The two measurements were averaged and used to calculate the BMI. Waist circumference was also measured in duplicate, midway between the lowest rib and the superior border of the iliac crest with a flexible tape measure ${ }^{(12)}$. Resting systolic and diastolic blood pressures were determined according to previously published guidelines ${ }^{(13)}$ and the mean of the three measurements was evaluated. Measurement reproducibility was tested in 238 controls (119 boys, 119 girls; mean age 11.5 (SD 3) and 11.5 (SD 2.9) years, respectively), with the reliability coefficient (Pearson) reaching $r=0.99,0.99,0.97,0.87$ and 0.77 for height, weight, waist circumference, systolic and diastolic blood pressures, respectively.

\section{Laboratory analyses}

Participants fasted for $12 \mathrm{~h}$ before a venous blood sample was drawn for the determination of glucose and lipids levels. HDL-C was obtained after precipitation of apoBcontaining lipoproteins using dextran sulfate and $\mathrm{MgCl}_{2}$. Plasma cholesterol, TAG and glucose levels were measured with commercially available kits (Johnson \& Johnson; Ortho Clinical Diagnostics, Rochester, NY, USA) in Vitros 250 and 750 auto-analysers.

\section{Definitions of terms and groups}

Participants were divided into three BMI groups according to cut-off values, adjusted for age and gender, derived from a large international study by Cole et $a l^{(14)}$. Subjects with a BMI corresponding to an adult $\mathrm{BMI}<25 \cdot 0 \mathrm{~kg} / \mathrm{m}^{2}$ were considered to be of normal weight; subjects with a BMI value in the range of $25 \cdot 0-29 \cdot 9 \mathrm{~kg} / \mathrm{m}^{2}$ were considered overweight; and those with a BMI $>30 \cdot 0 \mathrm{~kg} / \mathrm{m}^{2}$ were classified as obese. Elevated systolic or diastolic blood pressures were defined as a value at or above the 90th percentile for age, sex and height, according to the IV Arterial Hypertension Brazilian Guidelines ${ }^{(15)}$. If participants reported current use of any anti-hypertensive drugs, they were considered to have elevated blood pressure. The criteria used for HDL-C $(<45 \mathrm{mg} / \mathrm{dl})$ and TAG $(\geq 130 \mathrm{mg} / \mathrm{dl})$ level abnormalities were adopted from the First Brazilian Guideline in Preventing Atherosclerosis in Children and Adolescents ${ }^{(16)}$. The level of fasting glucose $\geq 100 \mathrm{mg} / \mathrm{dl}$ was considered abnormal according to American Diabetes Association ${ }^{(17)}$. Waist circumference values at or above the 90th percentile for age and sex were considered as criteria for abdominal obesity $^{(18-20)}$. MetS was defined as the presence of three or more of the above components, according to NCEP-ATP III ${ }^{(1)}$.

The Brazilian Economics Classification Criteria $^{(21)}$ were adopted to estimate the economic class of the participants' families, according to the monthly family income in US dollars: A (USD > 1847), B (USD 667 to 1847), C (USD 312 to 666), D (USD 164 to 311) and E (USD < 164). Schoolchildren were sorted into two groups: classes A, B and $\mathrm{C}$ (high income) and D and $\mathrm{E}$ (low income). Race was classified according to skin colour: white, Asian, black or mulatto. Considering that Brazilians are a miscegenation population, we divided the sample into two groups: white and non-white.

\section{Statistical analyses}

The database was built by double typing using Excel 2000 version. Statistical analyses were carried out by Epi-Info version $3 \cdot 2 \cdot 2$ (Centers for Disease Control and Prevention, Atlanta, GA, USA). MetS prevalence was estimated using a maximal error of $1 \cdot 4 \%$ for boys and $1 \cdot 2 \%$ for girls. The quantitative variables were expressed as mean (SD) and categorical variables in percentage and ranges of CI. The association between the MetS and BMI groups was tested using a $\chi^{2}$ test; age group, economic classes, sex and race were tested using Fisher's exact test. A $P$ value $<0 \cdot 05$ was considered statistically significant.

\section{Results}

Anthropometric characteristics and MetS laboratory results are shown in Table 1 . The prevalence of MetS in 
Table 1 Age, BMl and the components for MetS in schoolchildren from 6 to 16 years old in Maracai city, Sao Paulo, Brazil

\begin{tabular}{|c|c|c|c|c|c|c|}
\hline \multirow[b]{2}{*}{ Variables } & \multicolumn{2}{|c|}{ Total $(n 2170)$} & \multicolumn{2}{|c|}{ Boys (n 1103) } & \multicolumn{2}{|c|}{ Girls (n 1067) } \\
\hline & Mean & SD & Mean & SD & Mean & SD \\
\hline Age (years) & $11 \cdot 3$ & $3 \cdot 0$ & $11 \cdot 3$ & $3 \cdot 0$ & $11 \cdot 2$ & $3 \cdot 0$ \\
\hline Height (cm) & $145 \cdot 1$ & $17 \cdot 1$ & $143 \cdot 9$ & $15 \cdot 5$ & $146 \cdot 3$ & $18 \cdot 4$ \\
\hline Weight (kg) & $40 \cdot 6$ & $15 \cdot 9$ & $42 \cdot 0$ & $17 \cdot 6^{*}$ & $39 \cdot 2$ & $13 \cdot 9$ \\
\hline BMI $\left(\mathrm{kg} / \mathrm{m}^{2}\right)$ & $18 \cdot 5$ & $3 \cdot 8$ & $18 \cdot 8$ & $4 \cdot 1$ & $18 \cdot 3$ & 3.5 \\
\hline Waist circumference $(\mathrm{cm})$ & $64 \cdot 7$ & $9 \cdot 7$ & 65.9 & $10 \cdot 3+$ & $63 \cdot 4$ & $8 \cdot 7$ \\
\hline Systolic blood pressure (mmHg) & $99 \cdot 7$ & $13 \cdot 9$ & $100 \cdot 9$ & $14 \cdot 7+$ & $98 \cdot 4$ & $12 \cdot 9$ \\
\hline Diastolic blood pressure $(\mathrm{mmHg})$ & $64 \cdot 5$ & $10 \cdot 1$ & $64 \cdot 8$ & $10 \cdot 7$ & $64 \cdot 1$ & $9 \cdot 4$ \\
\hline Glucose $(\mathrm{mg} / \mathrm{dl})$ & $80 \cdot 21$ & $6 \cdot 3$ & $81 \cdot 05$ & $6 \cdot 4+$ & $79 \cdot 3$ & $6 \cdot 0$ \\
\hline TAG (mg/dl) & $77 \cdot 4$ & $32 \cdot 3$ & $74 \cdot 0$ & $32 \cdot 3+$ & $80 \cdot 8$ & $31 \cdot 9$ \\
\hline HDL-cholesterol (mg/dl) & $47 \cdot 2$ & $10 \cdot 5$ & $47 \cdot 0$ & $10 \cdot 3$ & $47 \cdot 4$ & $10 \cdot 6$ \\
\hline
\end{tabular}

MetS, metabolic syndrome.

${ }^{*} P<0.05$ and $+P<0.001$ for boys $v$. girls.

Table 2 Prevalence of MetS components among schoolchildren from 6 to 16 years old in Maracai city, Sao Paulo, Brazil

\begin{tabular}{|c|c|c|c|c|c|c|c|c|c|c|}
\hline \multirow[b]{2}{*}{ Variables } & \multicolumn{2}{|c|}{ Abdominal obesity } & \multicolumn{2}{|c|}{ Hypertension } & \multicolumn{2}{|c|}{ High glucose } & \multicolumn{2}{|c|}{ High TAG } & \multicolumn{2}{|c|}{ Low HDL-C } \\
\hline & $\%$ & $95 \% \mathrm{Cl}$ & $\%$ & $95 \% \mathrm{Cl}$ & $\%$ & $95 \% \mathrm{Cl}$ & $\%$ & $95 \% \mathrm{Cl}$ & $\%$ & $95 \% \mathrm{Cl}$ \\
\hline All $(n$ 2170) & $11 \cdot 2$ & $9 \cdot 9,12 \cdot 6$ & $9 \cdot 8$ & $8 \cdot 6,11 \cdot 2$ & 0.6 & $0 \cdot 3,1 \cdot 1$ & $6 \cdot 4$ & $5 \cdot 4,7 \cdot 5$ & $43 \cdot 2$ & $41 \cdot 1,45 \cdot 3$ \\
\hline Boys ( $n$ 1103) & $11 \cdot 5$ & $9 \cdot 7,13 \cdot 6$ & $11 \cdot 2$ & $9 \cdot 5,13 \cdot 3$ & $1 \cdot 1$ & $0.6,1.9$ & $6 \cdot 2$ & $4 \cdot 9,7 \cdot 8$ & $42 \cdot 3$ & $39 \cdot 4,45 \cdot 3$ \\
\hline Girls (n 1067) & $10 \cdot 8$ & $9 \cdot 0,12 \cdot 8$ & $8 \cdot 3$ & $6 \cdot 8,10 \cdot 2$ & $0 \cdot 1$ & $0,0.6$ & $6 \cdot 6$ & $5 \cdot 2,8 \cdot 3$ & $44 \cdot 0$ & $41 \cdot 1,47 \cdot 1$ \\
\hline White ( $n$ 1376) & $12 \cdot 1$ & $10 \cdot 4,13 \cdot 9$ & $10 \cdot 4$ & $8 \cdot 9,12 \cdot 2$ & 0.7 & $0 \cdot 4,1 \cdot 4$ & $6 \cdot 8$ & $5 \cdot 6,8 \cdot 3$ & $43 \cdot 8$ & $41 \cdot 2,46 \cdot 5$ \\
\hline Non-white ( $n$ 794) & $9 \cdot 6$ & $7 \cdot 7,11 \cdot 9$ & $8 \cdot 8$ & $7 \cdot 0,11 \cdot 1$ & 0.4 & $0 \cdot 1,1 \cdot 2$ & $5 \cdot 5$ & $4 \cdot 1,7 \cdot 4$ & $42 \cdot 1$ & $38 \cdot 6,45 \cdot 6$ \\
\hline Normal weight ( $n$ 1755) & 1.5 & $1 \cdot 0,2 \cdot 2$ & $6 \cdot 6$ & $5 \cdot 5,7 \cdot 9$ & 0.5 & $0 \cdot 3,1 \cdot 0$ & $3 \cdot 6$ & $2 \cdot 8,4 \cdot 6$ & $39 \cdot 9$ & $37 \cdot 6,42 \cdot 3$ \\
\hline Overweight (n 299) & $35 \cdot 8$ & $30 \cdot 4,41 \cdot 5$ & $17 \cdot 1$ & $13 \cdot 0,21 \cdot 8$ & $1 \cdot 0$ & $0 \cdot 2,2 \cdot 9$ & $18 \cdot 0$ & $13 \cdot 9,22 \cdot 9$ & $54 \cdot 5$ & $48 \cdot 7,60 \cdot 3$ \\
\hline Obese $(n 116)$ & $94 \cdot 0$ & $88 \cdot 0,97 \cdot 5$ & $39 \cdot 7$ & $30 \cdot 7,49 \cdot 2$ & 0.9 & $0,4 \cdot 7$ & $18 \cdot 1$ & $11 \cdot 6,26 \cdot 3$ & $62 \cdot 9$ & $53 \cdot 5,71 \cdot 7$ \\
\hline $6-9$ years old $(n 781)$ & $11 \cdot 4$ & $9 \cdot 3,13 \cdot 9$ & $10 \cdot 6$ & $8 \cdot 6,13 \cdot 1$ & $0 \cdot 1$ & $0,0 \cdot 8$ & 4.9 & $3 \cdot 5,6 \cdot 7$ & $39 \cdot 8$ & $36 \cdot 4,43 \cdot 4$ \\
\hline $10-16$ years old $(n 1389)$ & $11 \cdot 0$ & $9 \cdot 4,12 \cdot 8$ & $9 \cdot 4$ & $7 \cdot 9,11 \cdot 0$ & 0.9 & $0.5,1.5$ & $7 \cdot 2$ & $5 \cdot 9,8 \cdot 7$ & $45 \cdot 1$ & $42 \cdot 4,47 \cdot 7$ \\
\hline High income ( $n$ 967) & $14 \cdot 0$ & $11 \cdot 9,16 \cdot 3$ & $10 \cdot 5$ & $8 \cdot 7,12 \cdot 7$ & 0.8 & $0 \cdot 4,1 \cdot 7$ & $7 \cdot 0$ & $5 \cdot 5,8 \cdot 9$ & $41 \cdot 7$ & $38 \cdot 6,44 \cdot 9$ \\
\hline Low income ( $n$ 1203) & 8.9 & $7 \cdot 4,10 \cdot 7$ & $9 \cdot 2$ & $7 \cdot 7,11 \cdot 0$ & 0.4 & $0 \cdot 2,1 \cdot 0$ & $5 \cdot 8$ & $4 \cdot 6,7 \cdot 3$ & $44 \cdot 4$ & $41 \cdot 6,47 \cdot 3$ \\
\hline
\end{tabular}

MetS, metabolic syndrome; HDL-C, HDL cholesterol.

schoolchildren of our study was 3.6\% (95\% CI 2.9, 4.5), and marked differences in the occurrence of MetS were seen when subjects were examined by BMI category. MetS was present in 34.5\% (95\% CI 25.9, 43.9) of obese individuals while only $10 \cdot 7 \%(95 \% \mathrm{CI} 7 \cdot 4,14 \cdot 8)$ and $0 \cdot 3 \%(95 \% \mathrm{CI} 0 \cdot 1,0 \cdot 8)$ of overweight and normal-weight subjects, respectively, had the syndrome $(P<0 \cdot 001)$.

In contrast, prevalence of Mets did not differ statistically between boys $4 \cdot 2 \%(95 \%$ CI $3 \cdot 1,5 \cdot 6)$ and girls $3 \cdot 0 \%$ (95\% CI $2 \cdot 1,4 \cdot 3 ; P=0 \cdot 17)$. MetS prevalence was also similar among 6-9-year-old children 3.2\% (95\% CI $2 \cdot 1$, $4 \cdot 8)$ and 10-17-year-old adolescents 3.8\% (95\% CI $2 \cdot 9$, $5 \cdot 0 ; P=0.53)$ and between white $4 \cdot 1 \%(95 \%$ CI $3 \cdot 2,5 \cdot 4)$ and non-white $2 \cdot 6 \%(95 \%$ CI $1 \cdot 7, \quad 4 \cdot 1 ; \quad P=0 \cdot 09)$ individuals.

When socio-economic status was considered, significantly more high-income class schoolchildren had MetS than low-income class students ( $4 \cdot 7 \%$ (95\% CI 3.5, 6.2) v. $2.7 \%$ (95\% CI 1.9, 3.9); $P=0.023)$. Among the MetS components, the highest prevalence was low HDL-C ( $43 \cdot 2 \%)$, followed by abdominal obesity $(11 \cdot 2 \%)$, hypertension $(9 \cdot 8 \%)$, high blood TAG $(6 \cdot 4 \%)$ and glucose $\geq 100 \mathrm{mg} / \mathrm{dl}(0 \cdot 6 \%$; see Table 2$)$.

In the whole Maracaí sample, $52.9 \%$ presented with one or more MetS criteria, $13.8 \%$ had two or more components and $3.6 \%$ met at least three criteria, and were classified as MetS phenotype; only $0.7 \%$ displayed four or more MetS components. As shown in Table 3, the most frequent combination of the MetS components was low HDL-C, abdominal obesity and elevated blood pressure, followed by low HDL-C, high serum TAG and elevated blood pressure.

\section{Discussion}

As a consequence of compulsory elementary education, the sample investigated in the present study was very representative of the Maracai youth population, covering $95.6 \%$ of 6 -year-old children, as well as $83.3 \%$ and $81.9 \%$ of the students from 6 to 9 and 10 to 16 years old, respectively. Despite slightly less participation by adolescents (the latter age group), the percentage examined here was comparable to, if not more than, other studies. For example, in investigations performed in Bogalusa, only $59 \%$ of 17 -year-old students participated ${ }^{(22)}$.

In the present study, the overall prevalence of the MetS phenotype in the youth population of Maracai was $3.6 \%$, which is lower than that described in US adolescents (e.g. Cook et al. ${ }^{(18)}\left(4 \cdot 2 \%, 95 \%\right.$ CI 2·9, 5·4), de Ferranti et al. ${ }^{(7)}$ 
Table 3 Prevalence of multiple MetS components among schoolchildren from 6 to 16 years old in Maracai city, Sao Paulo, Brazil

\begin{tabular}{|c|c|c|c|c|c|c|c|c|}
\hline \multirow[b]{2}{*}{ Variables } & \multicolumn{2}{|c|}{$\geq 1$} & \multicolumn{2}{|c|}{$\geq 2$} & \multicolumn{2}{|c|}{$\geq 3$} & \multicolumn{2}{|c|}{$\geq 4$} \\
\hline & $\%$ & $95 \% \mathrm{Cl}$ & $\%$ & $95 \% \mathrm{Cl}$ & $\%$ & $95 \% \mathrm{Cl}$ & $\%$ & $95 \% \mathrm{Cl}$ \\
\hline All $(n 2170)$ & $52 \cdot 9$ & $50 \cdot 8,55 \cdot 1$ & $13 \cdot 8$ & $12 \cdot 4,15 \cdot 4$ & $3 \cdot 6$ & $2 \cdot 9,4 \cdot 5$ & $0 \cdot 7$ & $0 \cdot 4,1 \cdot 2$ \\
\hline Boys $(n 1103)$ & $52 \cdot 3$ & $49 \cdot 3,55 \cdot 3$ & $15 \cdot 0$ & $12 \cdot 9,17 \cdot 2$ & $4 \cdot 2$ & $3 \cdot 1,5 \cdot 6$ & 0.9 & $0.5,1 \cdot 7$ \\
\hline Girls (n 1067) & $53 \cdot 6$ & $50 \cdot 6,56 \cdot 6$ & $12 \cdot 7$ & $10 \cdot 7,14 \cdot 8$ & $3 \cdot 0$ & $2 \cdot 1,4 \cdot 3$ & $0 \cdot 6$ & $0 \cdot 2,1 \cdot 3$ \\
\hline White ( $n$ 1376) & $54 \cdot 1$ & $51 \cdot 4,56 \cdot 7$ & $14 \cdot 8$ & $13 \cdot 0,16 \cdot 8$ & $4 \cdot 1$ & $3 \cdot 2,5 \cdot 4$ & $0 \cdot 8$ & $0.4,1 \cdot 5$ \\
\hline Non-white $(n 794)$ & $51 \cdot 0$ & $47 \cdot 5,54 \cdot 5$ & $12 \cdot 1$ & $9 \cdot 9,14 \cdot 6$ & $2 \cdot 6$ & $1 \cdot 7,4 \cdot 1$ & $0 \cdot 6$ & $0.2,1 \cdot 6$ \\
\hline Normal weight ( $n$ 1755) & $46 \cdot 2$ & $43 \cdot 8,48 \cdot 5$ & $5 \cdot 6$ & $4 \cdot 6,6 \cdot 8$ & $0 \cdot 3$ & $0 \cdot 1,0 \cdot 8$ & $0 \cdot 1$ & $0,0.4$ \\
\hline Overweight ( $n$ 299) & $75 \cdot 9$ & $70 \cdot 7,80 \cdot 7$ & $37 \cdot 8$ & $32 \cdot 3,43 \cdot 6$ & $10 \cdot 7$ & $7 \cdot 4,14 \cdot 8$ & $2 \cdot 0$ & $3 \cdot 6,14 \cdot 2$ \\
\hline Obese $(n 116)$ & $96 \cdot 6$ & $91 \cdot 4,99 \cdot 1$ & $76 \cdot 7$ & $68 \cdot 0,84 \cdot 1$ & $34 \cdot 5$ & $25 \cdot 9,43 \cdot 9$ & $7 \cdot 8$ & $3 \cdot 6,14 \cdot 2$ \\
\hline $6-9$ years old $(n 781)$ & $50 \cdot 8$ & $47 \cdot 3,54 \cdot 4$ & $12 \cdot 5$ & $10 \cdot 3,15 \cdot 1$ & $3 \cdot 2$ & $2 \cdot 1,4 \cdot 8$ & $0 \cdot 3$ & $0,1 \cdot 0$ \\
\hline $10-16$ years old $(n 1389)$ & $54 \cdot 1$ & $51 \cdot 4,56 \cdot 7$ & $14 \cdot 5$ & $12 \cdot 7,16 \cdot 5$ & $3 \cdot 7$ & $2 \cdot 8,4.9$ & $1 \cdot 0$ & $0 \cdot 6,1 \cdot 7$ \\
\hline High income ( $n$ 967) & $52 \cdot 1$ & $48 \cdot 9,55 \cdot 3$ & $16 \cdot 3$ & $14 \cdot 1,18 \cdot 9$ & $4 \cdot 7$ & $2 \cdot 8,4 \cdot 9$ & $0 \cdot 9$ & $0 \cdot 5,1 \cdot 8$ \\
\hline Low income ( $n$ 1203) & $53 \cdot 6$ & $50 \cdot 7,56 \cdot 5$ & $11 \cdot 8$ & $10 \cdot 1,13 \cdot 8$ & $2 \cdot 7$ & $1.9,3.9$ & 0.6 & $0 \cdot 3,1 \cdot 2$ \\
\hline
\end{tabular}

$(9 \cdot 2 \%, 95 \%$ CI $7 \cdot 8,10 \cdot 6)$ and Duncan et al. $^{(19)}(6 \cdot 4 \%$, $95 \%$ CI $3 \cdot 8,8 \cdot 9))$. However, when socio-economic class was taken into consideration in our study population, MetS phenotype was twice as prevalent in high (4.7\%) than in low $(2.7 \%, P=0.023)$ income class students, representing $45 \%$ and $55 \%$ of the whole sample, respectively. We posit that this difference could be a consequence of less exercise and a higher energy diet in the high-income classes, since lower-income students generally walk to school and their school lunches are often their main meal of the day. The socio-economic distinction in MetS prevalence in this Maracai sample differs from the estimated incidence in the Brazilian population as a whole, of which high- and low-income class individuals comprise $65 \%$ and $35 \%$, respectively ${ }^{(21)}$. This differential distribution among socio-economic classes of the Maracai schoolchildren may have contributed to the lower $(3 \cdot 6 \%)$ overall MetS prevalence. Thus, we cannot consider Maracai city to be representative of the country. If the same socio-economic classification criteria were adopted for the entire country, we suppose that the MetS incidence in Brazilian schoolchildren would be higher than $3.6 \%$ and probably closer to the $4.7 \%$ rate found in the high-income class. To date, we do not have studies that could be considered representative of the Brazilian population and this is the first to consider socio-economic class.

Importantly, the low HDL-C $(<45 \mathrm{mg} / \mathrm{dl})$ cut-off value defined by the Brazilian Guidelines in Atherosclerosis Prevention for children and adolescents ${ }^{(15)}$, and used here, is arbitrary because of a lack of literature consensus. For the same reason, cut-off values adopted by others are also not standardised; for example, Moreno et al. ${ }^{(12)}$ considered low HDL-C value less than the 25 th percentile, Jessup and Harrel ${ }^{(23)}$ adopted HDL-C $\leq 35 \mathrm{mg} / \mathrm{dl}$, and Cook et al. ${ }^{(18)}$ and Duncan et al. ${ }^{(19)}$ considered HDL-C $\leq$ $40 \mathrm{mg} / \mathrm{dl}$. Analysing our data according to the parameter of HDL-C $<45 \mathrm{mg} / \mathrm{dl}$, low HDL-C was found in $43.2 \%$ of the whole sample, varying from $39.9 \%$ in the normalweight group to $62.9 \%$ in the obese group. However,
MetS prevalence was only $0.3 \%$ in the normal-weight group compared to $34.5 \%$ in the obese group, suggesting that the HDL-C cut-off we used has little or no impact in discriminating MetS phenotype in children and adolescents. A similar but opposite phenomenon occurred with the cut-off for blood glucose $(\geq 100 \mathrm{mg} / \mathrm{dl})$, which was detected in only $0.6 \%$ of the participants and did not differ between BMI groups. Perhaps, the glucose cut-off levels for children and adolescents should be less than $99 \mathrm{mg} / \mathrm{dl}$, which is commonly adopted. Consistent with this possibility, Tirosh et al. ${ }^{(24)}$ found that blood glucose levels above $86 \mathrm{mg} / \mathrm{dl}$ were an independent risk factor for type 2 diabetes in a prospective study with 13163 normoglycaemic young men. The prevalence of hypertension in Maracai schoolchildren was surprisingly high relative to adolescents in the USA (compare the present study $9 \cdot 8 \%(95 \% \mathrm{CI} 8 \cdot 6,11 \cdot 2)$ to the studies of Cook et al. ${ }^{(18)} 4.9 \%(95 \%$ CI 3.4, 6.4) and Duncan et al. $\left.{ }^{(19)} 8 \%(95 \% \mathrm{CI} 5 \cdot 3,10 \cdot 6)\right)$. However, our results are in line with another study conducted in the Brazilian population (e.g. Moura et al. ${ }^{(25)}$ 9.4\% (95\% CI $7 \cdot 8$, 11.02)). Furthermore, we demonstrate that hypertension prevalence is higher in overweight $(17 \cdot 1 \%)$ and obese (39.7\%) children. These data confirm the large impact obesity has on blood pressure and emphasise the necessity to clarify possible reasons for this elevated frequency of hypertension in Brazilian schoolchildren and the factors contributing to obesity.

Our study should be interpreted in light of its limitations. First, despite adopting cut-off points for our analysed parameters from standard panels, our definitions of MetS remain problematic due to imprecision inherent to any extrapolation from the adult to the paediatric population. Next, cholesterol levels, particularly HDL-C levels in males, are affected by puberty, which was not assessed by Tanner stage. Thus the high prevalence $(45 \cdot 1 \%)$ of low HDL-C among adolescents could be overestimated; however, low HDL-C was also found in $39 \cdot 8 \%$ of prepubertal children. Finally, despite the finding that MetS components vary according to race, the racial plurality 
and miscegenation in Brazil did not allow us to evaluate the MetS distribution according to this factor. Thus, we chose to denominate skin colour instead of race and divided the participants into white and non-white groups.

In conclusion, the clustered risk factors that characterise MetS were present during childhood, notably in overweight and obese schoolchildren, while being virtually absent in those with normal weights. Practitioners should be aware to detect these factors and to stimulate changes in lifestyle to avoid obesity, future cardiovascular morbidity and type 2 diabetes. In addition, our data also broadened the knowledge of MetS prevalence in developing countries while accounting for socio-economic classes, and provided information to help implement public health programmes and policies to approach the MetS problem.

\section{Acknowledgements}

Conflict of interest: There are no conflicts of interest.

Author's contributions: M.S. - student of the Post graduate Program of Medicine and Health Science, Londrina State University. He was responsible for collecting and analysing the data, and also participating in writing the paper. T.M. - Professor of Mathematics and Statistic, Londrina State University. She had a very important contribution in statistic accessory. A.J.F.C. - Professor of Medicine, Londrina State University. The entire work and manuscript version were under his supervision.

Acknowledgements: The authors thank The Ortho Clinical Diagnostics that kindly provided the biochemical kits, and the Labmed labimagem and Dr Joelson Laboratories that did the laboratory analyses; Selma M. Andrade, $\mathrm{PhD}$, for her technical support in clinical epidemiology; Janaina R. Dias, scholarship in scientific initiation; Noely Y.I. Ribeiro, Roberto de Almeida, Nelson Marquezelli, Benedito P. Salatini, Juliana Ribeiro, Desirene O. Teixeira, Edilene A. Custodio, Sonia M. Cavalcanti and Sandra R. Albertini, team of anthropometrical and blood data collectors.

\section{References}

1. Grundy SM, Brewer HB, Cleeman JI, Smith SC \& Lenfant C (2004) National Heart, Lung and Blood Institute; American Heart Association: Definition of metabolic syndrome: report of the National Heart, Lung and Blood Institute/ American Heart Association conference on scientific issues related to definition. Arterioscler Thromb Vasc Biol 24, $13-18$.

2. Isomaa B, Almgren P, Tuomi T, Forsen B, Latí K, Nissén M, Taskinen MR \& Groop L (2001) Cardiovascular morbidity and mortality associated with the metabolic syndrome. Diabetes Care 24, 683-689.

3. Daniels SR, Arnett DK, Eckel RH, Gidding SS, Hayman LL, Kumanyika S, Robinson TN, Scott BJ, Jeor SS \& Williams CL (2005) Overweight in children and adolescents pathophysiology, consequences, prevention and treatment. Circulation 111, 1999-2012.
4. Sinaiko AR, Jacobs DR Jr, Steinberger J, Moran A, Luepker R, Rocchini AP \& Prineas RJ (2001) Insulin resistance syndrome in childhood: associations of the euglycemic insulin clamp and fasting insulin with fatness and other risk factors. J Pediatr 139, 700-707.

5. Srinivasan SR, Myers L \& Berenson GS (2002) Predictability of childhood adiposity and insulin for developing insulin resistance syndrome (syndrome $\mathrm{X}$ ) in young adulthood: the Bogalusa Heart Study. Diabetes 51, 204-209.

6. Eckel RH, Grundy SM \& Zimmet PZ (2005) The metabolic syndrome. Lancet 365, 1415-1428.

7. de Ferranti SD, Gauvreau K, Ludwig DS, Neulfeld EJ, Newburger JW \& Rifai N (2004) Prevalence of the metabolic syndrome in American adolescents. Circulation 110, 2494-2497.

8. Kelishadi R (2007) Childhood overweight, obesity and the metabolic syndrome in developing countries. Epidemiol Rev 29, 62-76.

9. Alberti KG \& Zimmet PZ (1998) Definition, diagnosis and classification of diabetes mellitus and its complications, Part 1: diagnosis and classification of diabetes mellitus provisional report of a WHO consultation. Diabet Med 15, 539-553.

10. Balkau B \& Charles MA (1999) Comment on the provisional report from the WHO consultation: European Group for the Study of Insulin Resistance (EGIR). Diabet Med 16, 442-443.

11. Alberti KG, Zimmet P \& Shaw J, the IDF Epidemiology Task Force Consensus Group (2005) The metabolic syndrome: a new worldwide definition. Lancet 366, 1059-1062.

12. Moreno LA, Pineda I, Rodriguez G, Fleta J, Sarría A \& Bueno M (2002) Waist circumference for the screening of the metabolic syndrome in children. Acta Paediatr 91, 1307-1312.

13. National High Blood Pressure Education Program Working Group on High Blood Pressure in Children and Adolescents (2004) The fourth report on the diagnosis, evaluation, and treatment of high blood pressure in children and adolescents. Pediatrics 114, 555-576.

14. Cole TJ, Bellizzi MC, Flegal KM \& Dietz WH (2000) Establishing a standard definitions for child overweight and obesity worldwide: international survey. BMJ $\mathbf{3 2 0}$, 1240-1243.

15. IV Brazilian Guidelines in Arterial Hypertension Work Groups (2004) IV Brazilian guidelines in arterial hypertension. Arq Bras Cardiol 82, Suppl. 4, 7-22.

16. Back Giuliano I de C, Caramelli B, Pellanda L, Duncan B, Mattos S \& Fonseca FH, Sociedade Brasileira de Cardiologia (2005) I guideline in atherosclerosis prevention of childhood and adolescence. Arq Bras Cardiol 85, Suppl. 6, 4-36.

17. American Diabetes Association (2004) Diagnosis and classification of diabetes mellitus. Diabetes Care 27, Suppl. 1, S5-S10.

18. Cook S, Weitzman M, Auinger P, Nguyen M \& Dietz WH (2003) Prevalence of a metabolic syndrome phenotype in adolescents: findings from the third National Health and Nutrition Examination Survey, 1988-1994. Arch Pediatr Adolesc Med 157, 821-827.

19. Duncan GE, Li SM \& Zhou XH (2004) Prevalence and trends of a metabolic syndrome phenotype among US adolescents, 1999-2000. Diabetes Care 27, 2438-2443.

20. Hirschler V, Aranda C, Calcagno ML, Maccalini G \& Jadzinsky M (2005) Can waist circumference identify children with the metabolic syndrome? Arch Pediatr Adolesc Med 159, 740-744.

21. Brazilian Association of Research Companies - BARC (2003) Economical Classification Criteria of Brazil [electronic research]. http://www.abep.org (accessed September 2005).

22. Croft JB, Webber LS, Parker FC \& Berenson GS (1984) Recruitment and participation of children in a long-term 
study of cardiovascular disease: The Bogalusa Heart Study, 1973-1982. Am J Epidemiol 120, 436-448.

23. Jessup A \& Harrel JS (2005) The metabolic syndrome: look for it in children and adolescents, too! Clin Diabetes 23, 26-32.

24. Tirosh A, Shai I, Tekes-Manova D, Israeli E, Pereq D, Shochat T, Kochba I \& Rudich A; Israeli Diabetes Research
Group (2005) Normal fasting plasma glucose levels and type 2 diabetes in young men. $N$ Engl J Med 353, 1454-1462.

25. Moura AA, Silva MA, Ferraz MR \& Rivera IR (2004) Prevalence of high blood pressure in children and adolescents from the city of Maceio, Brazil. J Pediatr (Rio J) 80, 3-4. 